\title{
Effects of heat energy on morphology and properties of selective inhibition sintered high density polyethylene
}

\author{
D. Rajamani*, E. Balasubramanian \\ Centre for Autonomous System Research, Department of Mechanical Engineering, \\ Vel Tech Rangarajan Dr. Sagunthala R\&D Institute of Science and Technology, \\ Chennai - 600062, India \\ *E-mail: rajamanitamil1991@gmail.com
}

\begin{abstract}
This study provides an account of comprehensive experimentation and mechanical characterisation of high density polyethylene (HDPE) parts that are fabricated through an additive manufacturing process called selective inhibition sintering (SIS). Tensile and flexural test specimens are fabricated through selectively fusing the HDPE powder particles with a controlled heating environment. Morphological studies are performed to examine the coalescence of HDPE particles through sintering. Results indicate that, heat energy up to a threshold level of $28.48 \mathrm{~J} / \mathrm{mm}^{2}$ results in superior fusion of the HDPE particles, and further increase causes degradation of the structure. Surface roughness, tensile and flexural properties of SIS parts are compared with those of injection moulded parts for assessing their suitability to engineering applications.
\end{abstract}

Keywords: Selective inhibition sintering; heat energy; high density polyethylene; mechanical properties; surface quality.

\section{INTRODUCTION}

Additive manufacturing (AM) is a tool-less manufacturing process that enables the realisation of physical parts directly from digital designs through a sequential process of joining layers. In contrast to the conventional manufacturing that produces the parts through subtraction of material [1-2] through part specific tools and fixtures, AM provides an alternate fabrication option that is devoid of tools. Primary advantages of AM are the design freedom and time-compression that enable consumers to produce parts of complex shape in quick time [3]. AM eliminates many restrictions such as chemical degradation of materials due to high processing temperature, abnormal shrinkage, and cavity formation during crystallization due to the density difference between crystalline and amorphous phases associated with conventional techniques like moulding, casting, etc. [4]. At present, several AM technologies based on the additive principle are in use to fabricate functional prototypes, however, method of layer consolidation varies from one to other [5]. Selective laser sintering (SLS) provides wide ranging of material option encompassing metals, plastics and ceramics thus enables versatile applications [6]. In the SLS process, a three-dimensional object is built up layer-by-layer through selective sintering of powder particles with a tightly controlled high energy laser beam [7]. Despite the fact that, application of SLS in the development of 
complex engineering systems has led to enterprise-level solutions [8] and the need of maintaining costly laser systems curtails wide-spread usage thus necessitates alternative methods for selective sintering of fine powders [9].

Selective Inhibition Sintering (SIS) was originally developed by a research group at the University of Southern California [10] focused on inhibition of sintering at the layer boundary [11] through chemical or mechanical means. Whereas, the SLS process uses a laser to sinter the selected cross-sectional area, SIS process uses a low-cost heater to treat the powder. Unlike in SIS, the entire layer is cured through the heater leading to substantial reduction on part processing time. Precision delivery of inhibitor solutions through a guided delivery system is one of the key issues for maintaining the dimensional and surface integrity of the fabricated part.

In SIS, several factors including sintering (heater energy, heater feedrate, part bed temperature), printing (inhibitor type, printer feedrate, printer frequency) and material characteristics (composition, particle size) influence the part quality [12]. Hence, it is essential to pursue a detailed study of SIS parameters and their influence on part quality. It helps in determining optimum parameters for both the process and the product. Few studies have brought out the influence of SIS process variables on sintered part quality and performance characteristics. Asiabanpour et al. [13] examined the influence of process parameters on dimensional accuracy and surface quality characteristics of sintered parts using desirability approach. They have identified that heat energy, printer feedrate and layer thickness were mostly influencing the quality of SIS sintered parts. Authors' earlier studies dealt on numerical and experimental studies of sintering process and influence of selected SIS process parameters. Aravind et al. [14] and Arunkumar et al. [15] performed finite element analysis of single and multi-layer thermo-structural sintering interaction for diverse polymer materials. Balasubramanian et al. [16] studied the wear properties of high-density polyethylene parts produced by SIS process by varying different process variables. They proposed that the applied heat energy and layer thickness prominently influenced the wear resistance of sintered parts. Rajamani et al. [17] studied the shrinkage characteristics of SIS processed HDPE parts using RSM and desirability approach. They have found that the shrinkage of sintered specimens significantly influenced by heater energy and layer thickness.

In this work, test specimens were prepared as per ASTM standards with an application of different heat energies to fuse the particles. The effects of heat energy on the morphology of structure, surface roughness, tensile strength, and flexural strength properties of the sintered specimens were studied. Furthermore, sintering characteristics and fractured surface of specimens were analysed through scanning electron microscopy (SEM).

\section{SIS BASED FABRICATION OF POLYMER TEST SPECIMENS AND TESTING}

A technology demonstration system with a build envelope of $200 \times 200 \times 250 \mathrm{~mm}$ is developed for the proposed studies on HDPE powder (Figure 1). The preliminary modules of this system are a feed chamber, a reservoir for storing inhibitor solution, a delivery nozzle, a feed chamber, a ceramic heater and a recycle chamber. For delivering the inhibitor solution on HDPE particles that are spread on build platform, a delivery nozzle with a diameter of 0.1 $\mathrm{mm}$ is integrated. Supply specifications of HDPE particles indicate typical diameter of 25- 
$60 \mu \mathrm{m}$, glass transition temperature of $80^{\circ} \mathrm{C}$, melting temperature is $180{ }^{\circ} \mathrm{C}$ and density of $0.93 \mathrm{~g} / \mathrm{cm}^{3}$. In this study, CAD files corresponding to ASTM standards are created in the Solidworks modelling software and they are subsequently translated into stereolithography (.stl) format. Slic3r ${ }^{\circledR}$ software is used to slice the .stl file with specific layer thickness and convert them into G-codes. These G-Codes are imported into Pronterface ${ }^{\circledR}$ software for defining the traverse path of inhibitor head. HDPE powder is fed by a compacting roller to a specified layer thickness and inhibitor solution is deposited on each layer as per G-code. Each layer is inhibited at the part boundary through traversing of tubular ceramic heater on powder surface. The sequence of deposition, inhibition and sintering is repeated sequentially till realisation of full thickness.

The SIS process parameters that influence the part quality are layer thickness $(\mathrm{h})$, heater energy $(E)$, heater feed rate $\left(v_{h}\right)$, roller feed rate $\left(v_{r}\right)$, build tank temperature $\left(T_{b}\right)$, and stand-off distance (d). In this study, heater energy is varied within limits of 22.16 and 30.06 $\mathrm{J} / \mathrm{mm}^{2}$ (70 \% - $85 \%$ of melting point of HDPE), by maintaining layer thickness, heater feed rate, printer feed rate and built tank temperature at $0.1 \mathrm{~mm}$, of $3 \mathrm{~mm} / \mathrm{sec}, 120 \mathrm{~mm} / \mathrm{min}$ and of $50^{\circ} \mathrm{C}$, respectively. Distance between ceramic heater and polymer surface is maintained at $2 \mathrm{~mm}$.

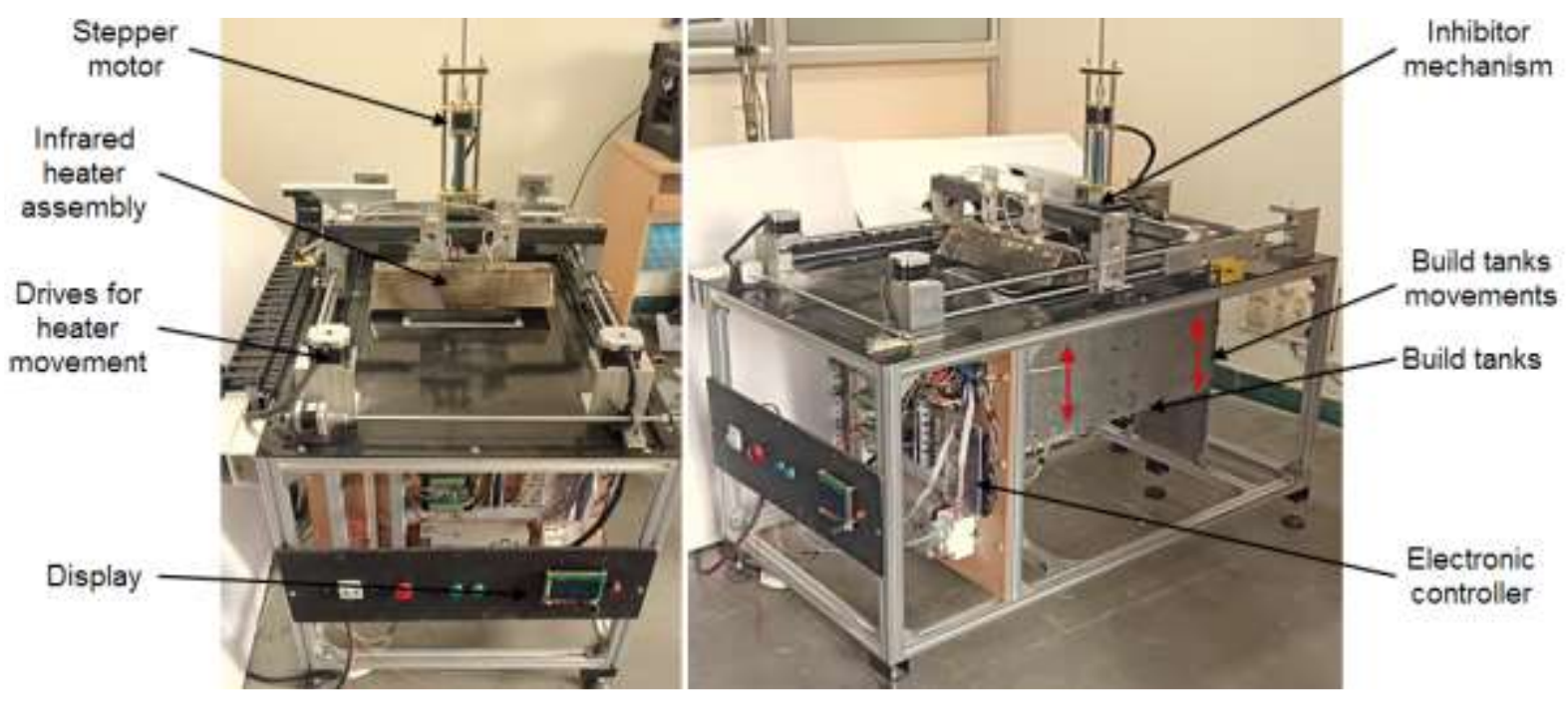

Figure 1. Developed SIS machine set-up

The impact of variation in heat energy on micro structure, surface roughness and strength of the sintered specimens is evaluated through iterative studies. The fabricated specimens are shown in Figure 2. Tensile and flexural properties of the sintered specimens are evaluated as per ASTM standards D 638 and D 790 respectively. A zwick/Roell make universal testing machine with a crosshead speed of $2 \mathrm{~mm} / \mathrm{min}$ is used for the proposed studies. Microstructure of the specimens and their fracture surfaces are examined with a Carl Zeiss Gemini SEM 500 scanning electron microscope at an operating voltage of $18 \mathrm{kV}$. These specimens are sputter coated with gold-palladium under vacuum condition for 75 seconds to avoid charging. Surface roughness of the specimen is evaluated with a universal 3D profilometer with white light interferometer setup. 

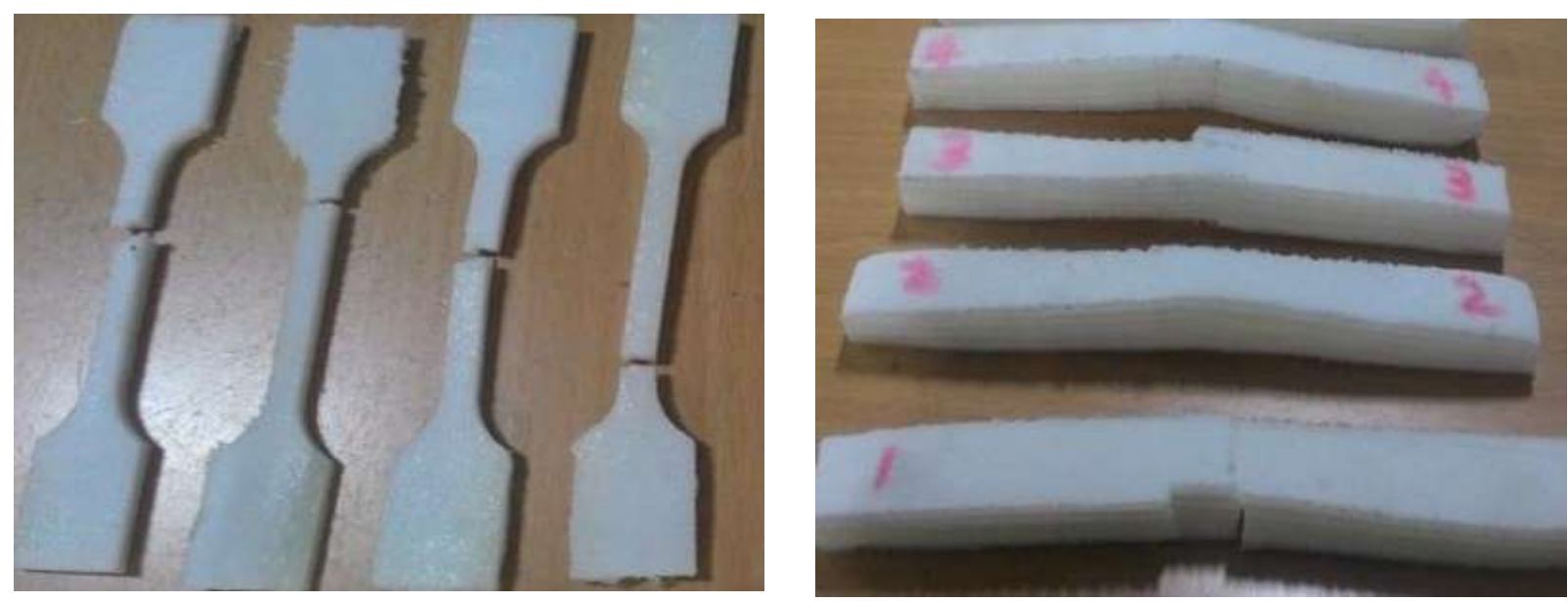

Figure 2. Sample tensile and flexural tested specimens

\section{RESULTS AND DISCUSSION}

\section{Effect of heat energy on Morphological development}

The surface morphologies of the sintered specimens built under different heat energies (HE) are shown in Figure 3(a-f). At a low $\mathrm{HE}=22.16 \mathrm{~J} / \mathrm{mm}^{2}$, the polymer particles were slightly fused together at points of contact and the individual particles can still be identified as shown in Figure 4a. At this condition, the polymer particles have changed into spherical from an irregular shape and their surface became smoother after the sintering process.

The surface morphology has been not much affected for the range of heat energies 23.74 to $26.9 \mathrm{~J} / \mathrm{mm}^{2}$, except a trivial increase in the amount of fusion between the powder particles. Nevertheless, some necks were found protruding from the sintering surface. They most likely caused by unsintered polymer particles beneath the surface. However, at $\mathrm{HE}=28.48 \mathrm{~J} / \mathrm{mm}^{2}$, the surface morphology of the selective inhibition sintered HDPE changed drastically, and a distinct surface structure was formed. This indicates that the flow of material is facilitated by better fusion of the HDPE particles coalesce together under the driving force of surface tension. However, some protrusions are apparent in the sintered surface. This can be attributed due to unsintered polymer particles underneath the surface or the insufficient heat energy input and time for the molten material to coalescence. As the heat energy was further increased as depicted in Figure $4 \mathrm{f}$ that, the presence of protrusions became less apparent and the number of pores on the surface decreased. They were likely caused by the high heater energy escalations, better fusion of polymer particles and facilitated a welldefined dense surface. As the heat energy was further increased above $30.09 \mathrm{~J} / \mathrm{mm}^{2}$, the molecular weight of sintered HDPE decreased more rapidly. The burning and degradation of HDPE is observed at heat energy above $30.09 \mathrm{~J} / \mathrm{mm}^{2}$. The produced heat energy is very high in comparison to laser based sintering process [18] which makes rapid sintering of powder particles in the desired regions. 

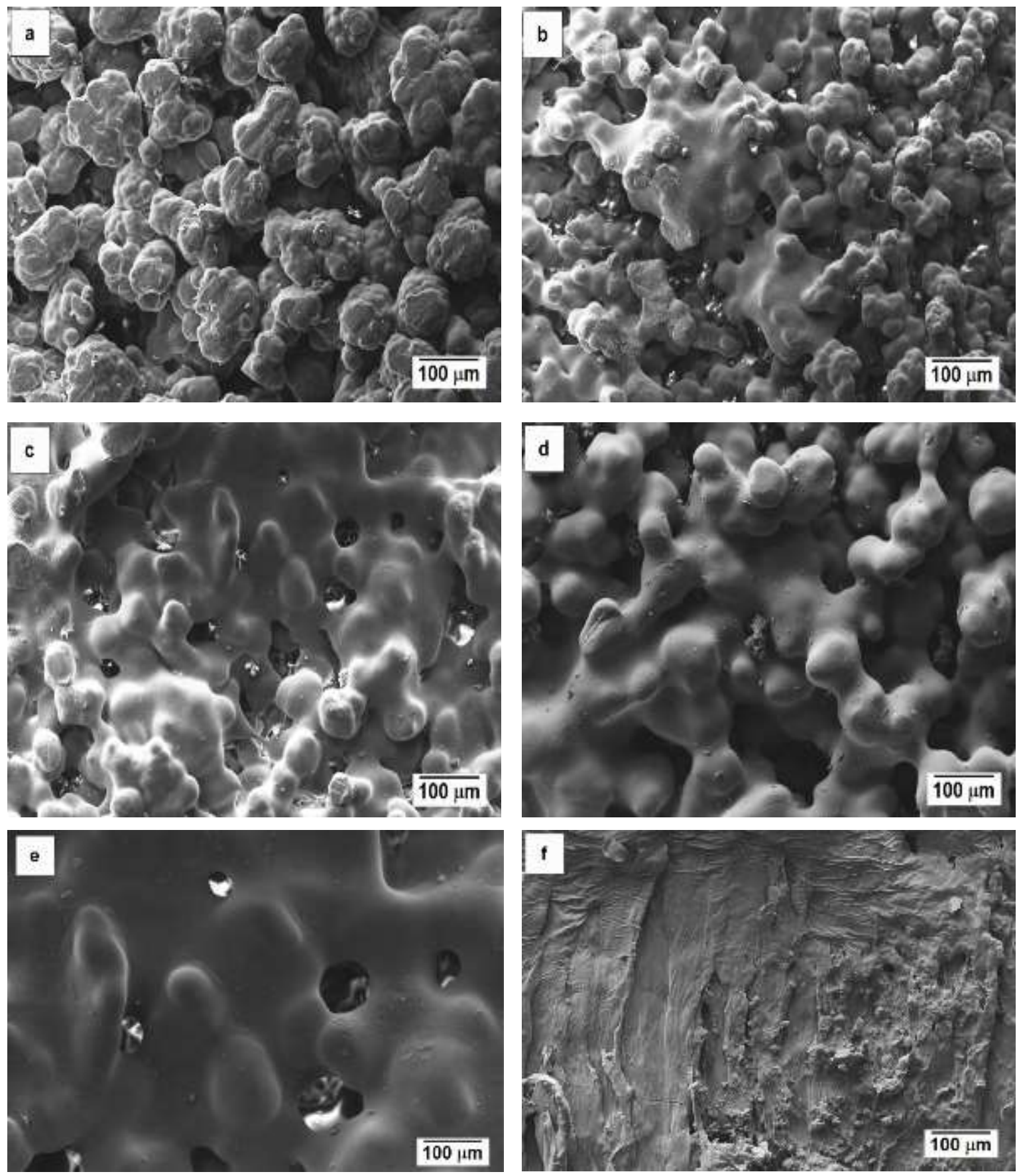

Figure 3. Surfaces of selective inhibition sintered HDPE specimens built with an heat energy $\left(\mathrm{J} / \mathrm{mm}^{2}\right)$ of (a) 22.16 ; (b) 23.74; (c) 25.32 ; (d) 26.9 ; (e) 28.48 ; and (f) 30.06 


\section{Effect of heat energy on mechanical properties}

The tensile strength of sintered specimen is evaluated for various input heat energies. During the applied heat energy in the range of 27-29 J/mm $\mathrm{mm}^{2}$ enhanced fusion of the HDPE particles are achieved and facilitated a more dense structure of the part specimens. However, at high heat energies, thermal volatilization of polymer is more stringent due to which mass of the parts are diminished resulted an increasing of porosity. Consequently, the mechanical properties such as tensile and flexural strength of sintered samples diminished. The variation of tensile strength and \% of elongation of SIS processed HDPE parts with different heat energy levels are depicted in Table 1.

It can be seen that the tensile strength increased systematically with the increase of heat energy. Maximum tensile strength was achieved when heat energy was maintained in the range of $27-29 \mathrm{~J} / \mathrm{mm}^{2}$ which is about $77 \%$ to $82 \%$ of melting point of HDPE and then began to decreases considerably. It is due to the cohesion and intermolecular attraction of the polymer particles is superior in these regimes and hence maximum tensile strength of HDPE is occurred. This is in agreement with the microstructure interpretations shown in Figure 3e. However, drop in tensile strength probably due to thermal degradation caused by an excessive exposure of the heat energy to the polymer powder causing the particles to burn. The degradation of polymers due to burning and growth of the voids by imprisoned gases augmented the porosity of polymer structure which in turn reduced the mechanical strength of fabricated parts. Also, the brittle nature with short-ranged tearing of test specimens has been observed at heat energy more than $28.48 \mathrm{~J} / \mathrm{mm}^{2}$. It has been found that, the maximum tensile strength of $26.95 \mathrm{MPa}$ was obtained at a heat energy of $28.48 \mathrm{~J} / \mathrm{mm}^{2}$, which was considerably higher than the injection- moulded specimen (21.4 MPa) [19].

Table 1 Tensile properties of SIS specimens

\begin{tabular}{lcccccc}
\hline Heat energy $\left(\mathrm{J} / \mathrm{mm}^{2}\right)$ & 22.16 & 23.74 & 25.32 & 26.90 & 28.48 & 30.06 \\
\hline Tensile strength $(\mathrm{MPa})$ & 22.22 & 22.88 & 24.04 & 24.70 & 26.95 & 24.95 \\
\% of elongation & 5.79 & 5.77 & 7.29 & 6.55 & 6.30 & 5.97 \\
\hline
\end{tabular}

Figure 4(a-c) shows the fractured surface of HDPE specimens subjected to tensile testing. The Figure 4a and c also depicts the formation of pores/voids in the fractured surfaces due to polymer pull-out. Further, failure may be occurred due to poor interfacial bonding and the presence of voids between layers. This voids act as stress concentrators and cause irregular dissemination of the normal stress above the cross-section of test specimen.

Experimentally evaluated tensile and flexural properties are presented in Table 2. While the variation in \% of elongation does not follow a distinct pattern, both tensile and flexural strengths reach peak levels at heat energy of $28.48 \mathrm{~J} / \mathrm{mm}^{2}$. Further increase in heat energy causes notable reduction in tensile and flexural properties. 

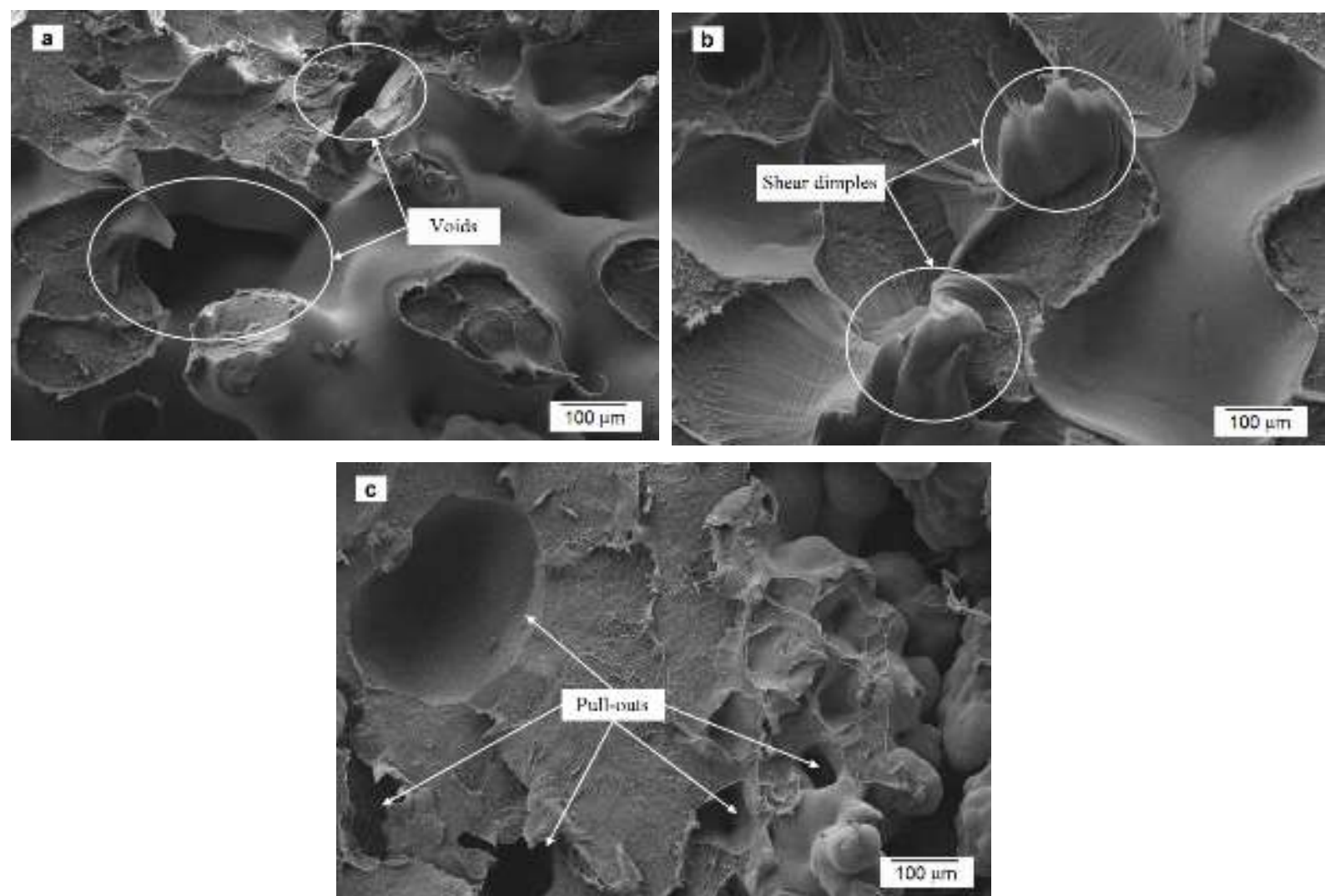

Figure 4. Tensile surfaces of selective inhibition sintered HDPE specimens built under a heat energy of $28.48 \mathrm{~J} / \mathrm{mm}^{2}$

Table 2 Flexural properties of SIS specimens

\begin{tabular}{lllllll}
\hline Heat energy $\left(\mathrm{J} / \mathrm{mm}^{2}\right)$ & 22.16 & 23.74 & 25.32 & 26.9 & 28.48 & 30.06 \\
\hline Flexural strength $(\mathrm{MPa})$ & 41.88 & 43.904 & 48.901 & 52.886 & 61.398 & 57.23 \\
\% of elongation & 23.01 & 12.93 & 17.29 & 16.38 & 16.94 & 14.81 \\
\hline
\end{tabular}

Figure 5(a-c) shows SEM micrograph of flexural fractured surface fabricated at a heat energy of $28.48 \mathrm{~J} / \mathrm{mm}^{2}$. It is evident from Figure $5 \mathrm{~b}$ that, there are interphase de-lamination at the cross-section of the sintered specimen due to the applied flexural load. An identical load was constantly applied on the specimen surface that created shear band along the middle section of specimen resulting in its breakage (Figure 5c).

From the Figure 5b, the voids are observed due to poor interfacial bonding between sintered particles. These voids can be acted as stress concentrators and cause irregular spreading of normal stress over the cross-section of test specimen. However, formation of voids and uneven sintering of polymer particles are observed comparatively higher in the case of specimens fabricated below the applied heat energy of $28.48 \mathrm{~J} / \mathrm{mm}^{2}$. Also an elongated shear dimples that coalesce normal to the loading axis are observed in Figure 5c. 
In addition, few voids and bulk cohesion of particles are observed in the fractured surface as seen in Figure 5a, this can be attributed due to non-uniform heat distribution during sintering.
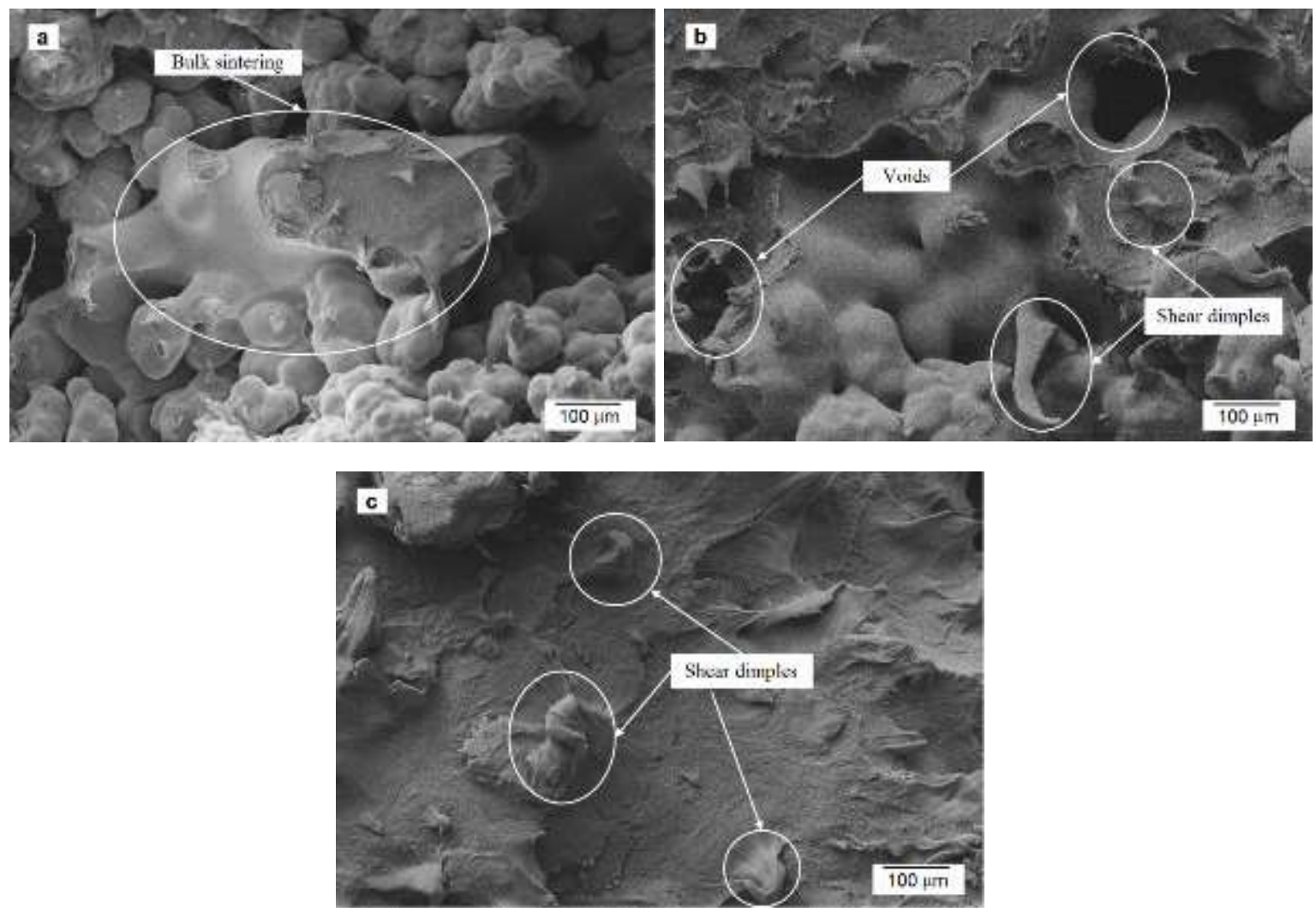

Figure 5. Fracture surfaces of SIS flexural specimens built with a heat energy of 28.48 $\mathrm{J} / \mathrm{mm}^{2}$

The appraised mechanical properties of SIS specimens are compared with injection moulded (IM) specimens which is given in Table 3. The SIS specimens exhibited good tensile and flexure strength of 26.95 and $61.4 \mathrm{MPa}$ respectively as compared to those of IM specimens.

Table 3 Comparison in the mechanical properties of SIS and IM specimens

\begin{tabular}{ccc}
\hline Samples & Tensile strength (MPa) & Flexural Strength (MPa) \\
\hline SIS - HDPE & 26.95 & 61.40 \\
$\left(\mathrm{HE}=28.48 \mathrm{~J} / \mathrm{mm}^{2}\right)$ & 21.40 & 48.30 \\
$\begin{array}{c}\text { Injection moulded } \\
(\mathrm{IM}) \text { HDPE [19] }\end{array}$ & 20 \\
\hline
\end{tabular}




\section{Effect of heat energy on Surface roughness}

Surface roughness of sintered specimens is evaluated in the directions that are parallel and transverse to sintering directions using Universal 3D Profilometer (Rtec Instruments, USA). Table 4 illustrates the effects of heat energy on surface roughness of the sintered HDPE specimens. Surface roughness $\left(\mathrm{R}_{\mathrm{a}}\right)$ highly depends upon particle size, sintering direction and density of the particle to achieve desired dimensional accuracy [20]. In fact, the heat energy and sintering direction of SIS process are the crucial parameters to enhance the surface quality of fabricated specimens. However, there is not much difference has been seen in $\mathrm{R}_{\mathrm{a}}$ between the parallel and perpendicular directions of the sintering as per the Table 4. It is observed that the surface roughness initially decreased with increasing $\mathrm{HE}$ and reached a minimum value of $18.7 \mu \mathrm{m}$, at $\mathrm{HE}=28.48 \mathrm{~J} / \mathrm{mm}^{2}$. Further increase in heat energy results in increase of $\mathrm{R}_{\mathrm{a}}$. The maximum surface roughness of $37.4 \mu \mathrm{m}$ and the minimum roughness value of $18.7 \mu \mathrm{m}$ is obtained at the sintering energy of $22.16 \mathrm{~J} / \mathrm{mm}^{2}$ and $28.48 \mathrm{~J} / \mathrm{mm}^{2}$, respectively. The corresponding three-dimensional surface texture of sintered samples is depicted in Figure 6 (a-b). On comparing the both surfaces, the specimen fabricated under a heat energy of $28.48 \mathrm{~J} / \mathrm{mm}^{2}$ has least peaks due to the effective sintering of particles which exhibits abridged surface roughness.

At low heat energy, certain powder particles receive an inadequate heat energy resulting in unfortunate fusion of these particles to adjacent particles. These particles become isolated from the surface of the layer send-off the voids and the coalescence process has originated or it might halt during sintering, resulting a rough surface structure. As the heat energy increased beyond $28.48 \mathrm{~J} / \mathrm{mm}^{2}$, the surface superiority seemed to deteriorate giving a rough surface. This is due to the excessive heat energy produces bubbles underneath the surface that affected the surface finish of the SIS specimens. Hence, it is recommended to perform sintering about $85 \%$ of melting point of $\operatorname{HDPE}\left(28.48 \mathrm{~J} / \mathrm{mm}^{2}\right)$ to obtain good surface finish characteristics.

Table 4 The variations of surface roughness of SIS HDPE with heat energy

\begin{tabular}{lcccccc}
\hline Heat energy $\left(\mathrm{J} / \mathrm{mm}^{2}\right)$ & 22.16 & 23.74 & 25.32 & 26.90 & 28.48 & 30.06 \\
\hline $\begin{array}{l}\text { Surface roughness }(\mu \mathrm{m}) \\
\begin{array}{l}\text { Parallel to sintering } \\
\text { direction }\end{array}\end{array}$ & 37.4 & 32.9 & 25.4 & 23.8 & 18.7 & 22.4 \\
$\begin{array}{l}\text { Surface roughness }(\mu \mathrm{m}) \\
\begin{array}{l}\text { Perpendicular to sintering } \\
\text { direction }\end{array}\end{array}$ & 39.9 & 32.5 & 26.7 & 24.2 & 20.9 & 22.6 \\
\hline
\end{tabular}



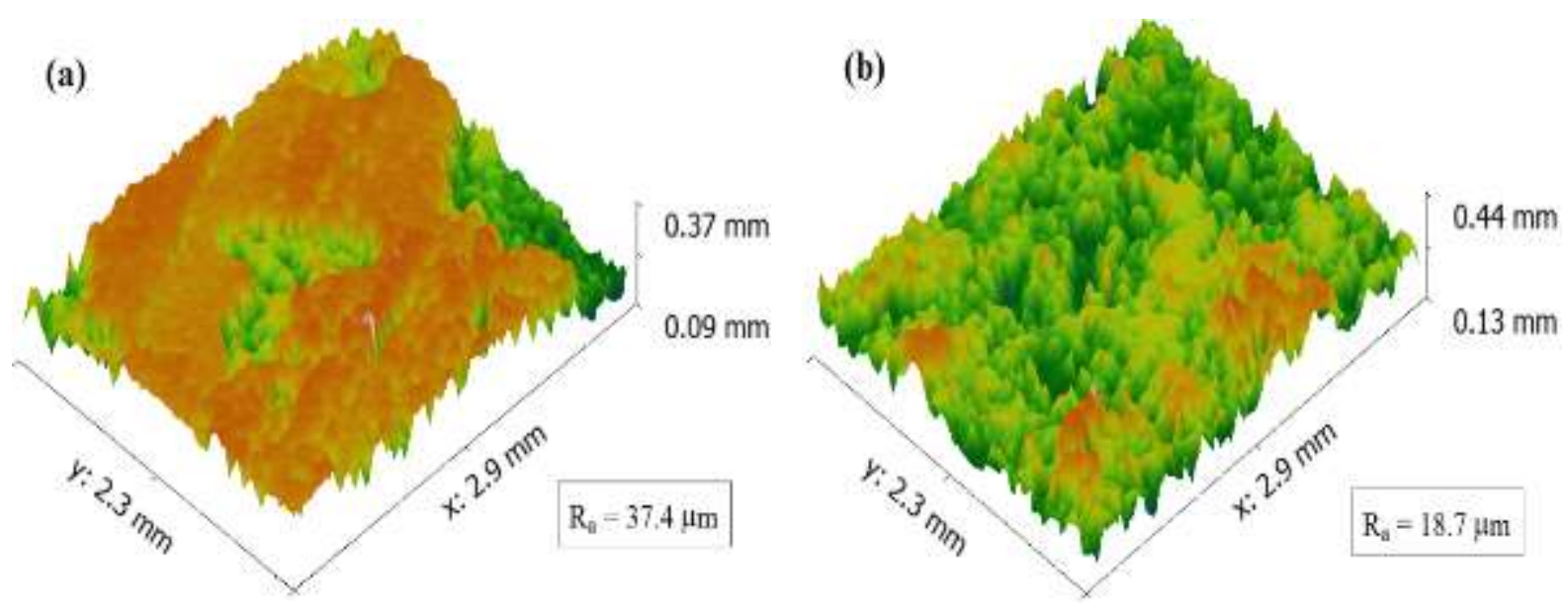

Figure 6. 3D surface topography of sintered specimen (a) $\mathrm{HE}=22.16 \mathrm{~J} / \mathrm{mm}^{2}$, and (b) $=$ $28.48 \mathrm{~J} / \mathrm{mm}^{2}$

\section{CONCLUSIONS}

A comprehensive effort in rapid fabrication of parts using SIS of HDPE particles at various input heat energy levels are realized through various experimental studies. Sintered HDPE specimens built at heat energy of about $28.48 \mathrm{~J} / \mathrm{mm}^{2}$ exhibited highest tensile and flexural strengths and obtained improved surface quality. Observations through SEM micrographs indicated that, increase in heat energy up to $28.48 \mathrm{~J} / \mathrm{mm}^{2}$ resulted in better cohesion of polymer particles with reduced pores and voids. Stress-strain plots of SIS specimens exhibited $20.6 \%$ greater tensile strength and $21.3 \%$ higher flexural strength in comparison with IM parts. Increase of heat energy from $22.16 \mathrm{~J} / / \mathrm{mm}^{2}$ has decreasing trend in surface roughness. However, minimum surface roughness of $\mathrm{R}_{\mathrm{a}}=18.7 \mu \mathrm{m}$ is observed at $28.48 \mathrm{~J} / \mathrm{mm}^{2}$ and further increase of heat diminishes the surface quality of the parts. Moreover, the micrographs of fractured surfaces showed that, the phenomenon of "pull-out" occurred causing the failure of material. The results suggested that SIS can be well utilized to fabricate functional parts and prototypes with less cost in comparison to other AM methods.

\section{ACKNOWLEDGEMENTS}

Authors would like to acknowledge the support received from Armament Research Board, Defence Research and Development Organization (DRDO), Govt. of India, under the project no. ARMREB/MAA/2015/167 titled "Near net shape components through automated selective inhibition sintering process for small armament applications". 


\section{REFERENCES}

[1] ISO/ASTM Standard 52900. Additive Manufacturing-General PrinciplesTerminology. ISO/ASTM International, Switzerland; 2015.

[2] Degrange J. Paradigm shift from rapid prototyping to direct manufacturing. Proceedings from the SLS user group meeting. Orlando; 2003.

[3] Wohlers. Rapid prototyping tooling and manufacture. Annual state of the Industry report. Wohlers associates. USA; 2003.

[4] Jauffres D, Lame O, Vigier G, Dore F, Douillard T. Sintering mechanisms involved in high-velocity compaction of nascent semi crystalline polymer powders. Acta Materialia 2009; 57: 2550-2559.

[5] Khalil Y, Kowalski A, Hopkinson N. Influence of energy density on flexural properties of laser-sintered UHMWPE. Additive Manufacturing 2016; 10: 67-75.

[6] Gu D, Zhang G. Selective laser melting of novel nanocomposite parts with enhanced tribological performance. Virtual and Physical Prototyping 2013; 8 (1): 11-18.

[7] Calignano F, Manfredi D, Ambrosio E.P, Luliano L, Fino P. Influence of process parameters on surface roughness of aluminium parts produced by DMLS. International Journal of Advanced Manufacturing Technology 2013; 67 (9): 27432751.

[8] Zhang J, Khoshnevis B. Selective separation (SSS) A new layer based additive manufacturing approach for metals and ceramics. Proceedings from the $26^{\text {th }} \mathrm{SFF}$ symposium, Austin, TX. 2015; 71-79.

[9] Hopkinson N, Erasenthiran P. High speed sintering- Early research into a new rapid manufacturing process. Proceedings from the $15^{\text {th }} \mathrm{SFF}$ symposium, Austin, Texas, 2004; 312-320.

[10] Khoshnevis B, Asiabanpour B, Mojdeh M, Koraishy B, Palmer K, Deng Z. SIS- A new SFF method based on powder sintering. Proceedings from the $13^{\text {th }}$ SFF symposium, Austin, Texas, 2002; 440-447.

[11] Asiabanpour B, Palmer K, Khoshnevis B. An experimental study of surface quality and dimensional accuracy for selective inhibition of sintering. Rapid Prototyping Journal 2004; 10 (3): 181-192.

[12] Asiabanpour B. An experimental study of factors affecting the selective inhibition sintering process. PhD Thesis, University of Southern California, 2003.

[13] Asiabanpour B, Khoshnevis B, Palmer K. Advancements in the selective inhibition sintering process development. Virtual Physical Prototyping 2006; 1(1): 43-52.

[14] Aravind A, Arunkumar P, Balasubramanian E. Comparative study of High performance Polymers in Selective Inhibition Sintering process through Finite Element Analysis. Journal of Polymers and Polymer Composites 2017; 25(3): 199202.

[15] Arunkumar P, Balasubramanian E, Chandrasekhar U. Investigation on multi-layer selective inhibition sintering process using finite element analysis. Materials Today Proceedings 2017; 4(2): 2439-2444.

[16] Balasubramanian E, Rajamani D, Arunkumar P. Modeling and prediction of optimal process parameters in wear behaviour of selective inhibition sintered high density polyethylene parts. Progress in Additive Manufacturing 2018; 3 (3): 109-121. 
[17] Rajamani D, Balasubramanian E, Arunkumar K, Silambarasan M, Bhuvaneshwaran G. Experimental investigations and parametric optimization of process parameters on shrinkage characteristics of selective inhibition sintered high density polyethylene parts. Experimental Techniques 2018; 42 (6): 631-644.

[18] Hong Ho HC, Cheung WL, Gibson I. Morphology and properties of selective laser sintered bisphenol a polycarbonate. Industrial and Engineering Chemistry Research 2003; 42: 1850-1862

[19] Overview of materials for high density polyethylene (HDPE), Injection Moulded. Retrieved from http://www.matweb.com; July 2018.

[20] Sachdeva A, Sharanjit S, Sharma VS. Investigating surface roughness of parts produced by SLS process. International Journal of Advanced Manufacturing Technology 2013; 64: 1505-1516. 